\title{
Identification of secondary fatty alcohols in atmospheric aerosols in temperate forests
}

\author{
Yuzo Miyazaki $^{1}$, Divyavani Gowda ${ }^{1, a}$, Eri Tachibana ${ }^{1}$, Yoshiyuki Takahashi ${ }^{2}$, and Tsutom Hiura ${ }^{3}$ \\ ${ }^{1}$ Institute of Low Temperature Science, Hokkaido University, Sapporo, 060-0819, Japan \\ ${ }^{2}$ National Institute for Environmental Studies, Tsukuba, 305-8506, Japan \\ ${ }^{3}$ Field Science Center for Northern Biosphere, Hokkaido University, Tomakomai, 053-0035, Japan \\ a now at: RIKEN Center for Integrative Medical Science, Yokohama, 230-0045, Japan
}

Correspondence: Yuzo Miyazaki (yuzom@lowtem.hokudai.ac.jp)

Received: 23 January 2019 - Discussion started: 18 February 2019

Revised: 28 April 2019 - Accepted: 6 May 2019 - Published: 24 May 2019

\begin{abstract}
Fatty alcohols (FAs) are major components of surface lipids (waxes) and can act as surface-active organic aerosols in the atmosphere, influencing chemical reactions, particle lifetimes, and the formation of cloud droplets and ice nuclei. However, studies on the composition and source of the FAs in atmospheric aerosols are very limited. In this study, we identified five secondary FAs (SFAs) with $\mathrm{C}_{27}$ and $\mathrm{C}_{29}$ from aerosol samples collected throughout 1 year at two different deciduous forest sites in Japan. Fatty diols, such as $n$-heptacosan-5,10-diol, were identified in atmospheric aerosols for the first time. Among the identified SFAs, $n$ nonacosan-10-ol was the most abundant compound, followed by $n$-nonacosan-5-10-diol at both of the forest sites. Concentrations of the SFAs exhibited distinct seasonal variation, with pronounced peaks during the growing season at each forest site. The SFAs showed significant correlation with sucrose, which is used as a molecular tracer of pollen. A significant fraction of the SFAs was attributed to the submicrometer particles in the growing season. The results indicate that they originated mostly from plant waxes and could be used as useful tracers for primary biological aerosol particles.
\end{abstract}

\section{Introduction}

Lipids can be effectively used as molecular markers of terrestrial and marine sources of atmospheric aerosols (e.g., Gagosian et al., 1981). In the terrestrial environment, different organisms contain a variety of long-chain alcohols (fatty alcohols; FAs) because of the diversity of pathways used by the biota for the synthesis of molecules and other compounds. Most fatty alcohols occur in biota as waxes covering parts of plants, which are useful for preventing desiccation, protection from bacterial attack, UV screening, and so on (e.g., Dahl et al., 2005). Because the main function of plant waxes is to reduce water loss through evaporation, waxes originating from this source tend to have longer chain lengths. The most prominent chain lengths are $\mathrm{C}_{26}$ to $\mathrm{C}_{30}$ (Tulloch, 1976). Once emitted into the atmosphere, FAs in atmospheric aerosols can act as tracers of primary biological aerosol particles (PBAPs) (Simoneit et al., 2004). Previous studies estimated global emissions of PBAPs mostly based on the abundance of fungal spores (e.g., the sugar mannitol as a biotracer) and bacteria (Carslaw et al., 2010). Among possible compounds of PBAPs, however, our knowledge is very limited on the abundance, emission mechanisms, and atmospheric behavior of FAs originated from plants. Possible emission drivers, such as temperature, light intensity, and local wind speed, likely vary with types and sources of PBAPs.

FAs are known as major components of surface lipids (waxes) with chains varying between $\mathrm{C}_{20}$ and $\mathrm{C}_{34}$ carbon atoms (Mudge, 2005). Fatty alcohols are composed of longchain hydrocarbons and hydroxyl $(-\mathrm{OH})$ groups, which can congregate at the aqueous surface and can act as surfaceactive organic aerosols (OAs). These aerosols can cause gases to transfer into the aqueous phase as atmospheric particles and prevent evaporation, which influences chemical reactions, particle lifetimes, fog/cloud droplets, and ice nuclei (IN) (Gill et al., 1983; Cantrell and Robinson, 2006; Knopf et al., 2018). In particular, biogenic particles such as fun- 
gal spores and bacteria can serve as a source of IN macromolecules, implying that IN macromolecules are therefore derived from a variety of biological or biogenic particles (Pummer et al., 2015). Long-chain alcohols show appreciable IN activity if they are crystallized into well-defined monolayers. This depends on chain length, the position of the $\mathrm{OH}$ group, and any substitutions on the side chains (Popovitz-Biro et al., 1994).

Oros and Simoneit (2001a) observed $n$-nonacosan-10-ol, a secondary FA (SFA), in smoke samples from conifers subjected to controlled burning. In addition, an alkanediol $n$ nonacosan-5-10-diol was identified in ambient aerosol samples collected in the western North Pacific during the ACEAsia campaign (Simoneit et al., 2004). Some common alkanols were also found within ambient aerosols at urban and remote island sites and are thought to have been emitted to the atmosphere via biomass burning (Oros and Simoneit, 2001a, b). These studies also indicate an input of waxes from forests consisting of both soft and hardwoods. However, studies are very limited on the composition and sources of FAs in atmospheric aerosols obtained in the vicinity of source regions, such as forest environments.

In this study, we used gas chromatography-mass spectrometry (GC-MS) to identify five SFAs found in atmospheric aerosols, both in submicrometer particles and total suspended particulate matter (TSP), sampled throughout 1 year within canopies of two different temperate forests in Japan. We discuss their possible sources based on their seasonal variations in mass concentration found at the two forest sites.

\section{Experimental}

\subsection{Aerosol sampling}

Ambient aerosol samplings were conducted at two different forest sites in Japan (Fig. 1): one is the Tomakomai (TMK) experimental forest $\left(42^{\circ} 43^{\prime} \mathrm{N}, 141^{\circ} 36^{\prime} \mathrm{E}\right)$ of Hokkaido University, located in northern Japan; and the other is the FujiHokuroku (FHK) flux research site $\left(35^{\circ} 26^{\prime} \mathrm{N}, 138^{\circ} 45^{\prime} \mathrm{E}\right)$. All the aerosol samples were collected on quartz fiber filters $(25 \mathrm{~cm} \times 20 \mathrm{~cm})$, which were precombusted at $410^{\circ} \mathrm{C}$ for $6 \mathrm{~h}$ to remove any contaminants. Descriptions of each site are given in the following subsections.

\subsubsection{Tomakomai (TMK) experimental forest}

The TMK site is situated in a cool temperate zone, with its southern boundary adjacent to Tomakomai city and its industrial port area facing the Pacific Ocean. The mixed cool temperate forest consists of mature and secondary deciduous forest and man-made coniferous forest with various types of forest floor cover (Hiura, 2001, 2005). Tree species include Mongolian oak (Quercus crispula); mono maple (Acer pictum); Korean whitebeam (Aria alnifolia); Japanese lin-

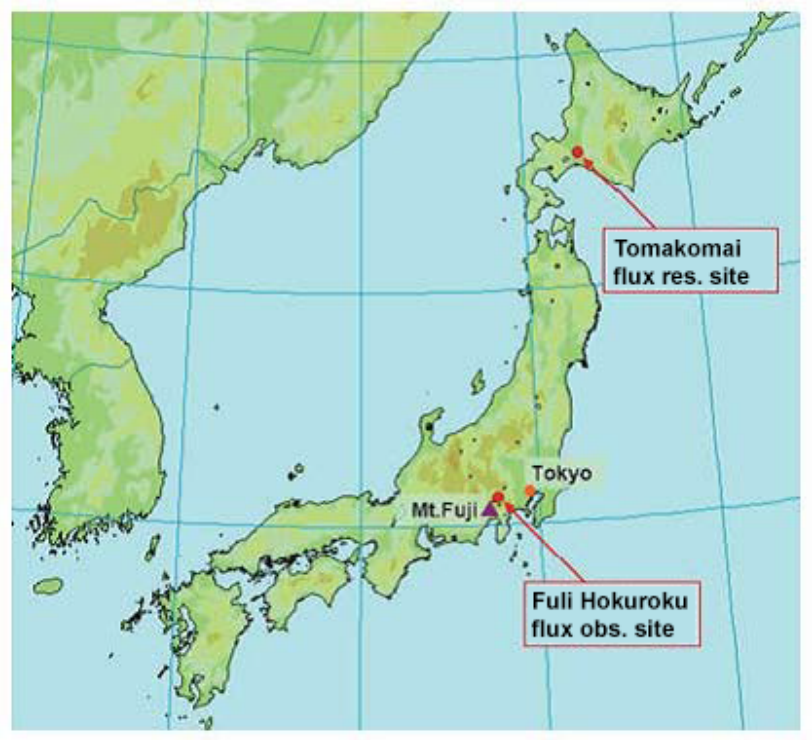

Figure 1. Locations of the two forest sites where aerosol sampling was performed.

den (Tilia japonica); and the planted species Japanese larch (Larix leptolepsis), sakhalin fir (Abies sachalinensis), and sakhalin spruce (Picea glehnii) (Hiura, 2005). The height of the main trees ranges between 15 and $20 \mathrm{~m}$, and the leaf area index (LAI) is within a range of $3.3-4.9 \mathrm{~m}^{2} \mathrm{~m}^{-2}$ (Hiura, 2001). The soil consists of shallow and unweathered volcanogenic regosols. The predominant local wind direction in autumn and winter is from the north, originating in the forested areas. In contrast, air transported from the south (the coastal urban area) is dominant in summer.

At the TMK site, both TSP and submicrometer aerosol samples were collected continuously in parallel using two high-volume air samplers (HVASs; model 120SL, Kimoto Electric, Osaka, Japan) at an altitude of $\sim 18 \mathrm{~m}$ above the forest floor of the research site (Müller et al., 2017). A cascade impactor (CI; model TE-234, Tisch Environmental, Cleves, OH, USA) was attached to one of the two HVASs to collect size-segregated particles with five stages at a flow rate of $1130 \mathrm{~L} \mathrm{~min}^{-1}$. We used analytical results obtained from the bottom stage of the impactor, which collected particles with aerodynamic diameter smaller than $0.95 \mu \mathrm{m}$. Aerosol particles within this size range are referred to as submicrometer particles. The sampling was taken continuously with a duration of approximately 1 week for each sample, from January to December in 2015. Collected filter samples were individually stored in glass jars with a Teflon-lined screw cap at $-20^{\circ} \mathrm{C}$ to limit the chance for chemical reactions on the filter and the loss of volatile compounds. In total, 23 sample sets were obtained at this site for both TSPs and submicrometer particles. 


\subsubsection{Fuji-Hokuroku (FHK) flux research site}

The FHK research site is located at the base of Mt. Fuji in Fujiyoshida city, Yamanashi, Japan (Fig. 1) (e.g., Mochizuki et al., 2015; Urakawa et al., 2015). The urban area of Fujiyoshida city is located about $8 \mathrm{~km}$ northeast of the site. The vegetation type is Larix kaempferi plantation, which was planted uniformly 55 years ago over 150 ha. Tree height is approximately $20-25 \mathrm{~m}$. LAI was estimated to be $2.8 \mathrm{~m}^{2} \mathrm{~m}^{-2}$ based on the leaf mass abundance in 2006 (Takahashi et al., 2015). After tree thinning at the site in 2014, the leaf mass abundance in 2015 and 2016 decreased to $80 \%$ and $96 \%$ of that in 2006, respectively. The site is surrounded by coniferous and broad-leaved mixed forests. A meteorological tower of $32 \mathrm{~m}$ height and a steel scaffold of $20 \mathrm{~m}$ height for tree surveys are situated at the center of the forest site. The soil type is coarse-grained volcanic ash. The forest floor is predominantly covered with Dryopteris crassirhizoma. The FHK site is located on a slope in the northern foothills of Mt. Fuji, and the dominant wind direction is characterized by two modes throughout a year: from the north (valley wind) in daytime and from the south (mountain wind) in nighttime (Takahashi et al., 2015).

TSP sampling was conducted at a height of $16 \mathrm{~m}$, just beneath the larch canopy, using a HVAS (model 120SL, Kimoto Electric, Osaka, Japan) mounted on the $20 \mathrm{~m}$ steel scaffold. The aerosol samples were collected from January 2015 to December 2016 with a sampling duration for each aerosol sample of $\sim 2$ weeks. The flow rate of the TSP sampling was approximately $\sim 600 \mathrm{~L} \mathrm{~min}^{-1}$. In total, 15 and 17 samples were analyzed, obtained at the FHK site for the year 2015 and 2016, respectively. The collected filter samples were kept frozen at $-20^{\circ} \mathrm{C}$ until analysis. It is noted that the difference in the sampling duration at the two sampling sites might not significantly affect our conclusions, because we discuss the seasonal changes of the aerosol concentrations whose timescale is much longer than that of the aerosol sampling (1-2 weeks).

\subsection{Analytical procedure with gas chromatography-mass spectrometry (GC-MS)}

For the aerosol samples, a filter cut of $3.8 \mathrm{~cm}^{2}$ was extracted with dichloromethane/methanol $(2: 1, v / v)$ and the $-\mathrm{OH}$ functional groups in the extracted samples were reacted with a mixture of $50 \mu \mathrm{L}$ of $N, O$-bis-(trimethylsilyl) trifluoroacetamide (BSTFA), $1 \%$ trimethylsilylchloride, and $10 \mu \mathrm{L}$ pyridine to form trimethylsilyl (TMS) ethers. The TMS derivatives were then analyzed for the presence of the compounds listed above using a capillary gas chromatograph (GC7890, Agilent) equipped with a fused silica capillary column (DB-5MS, Agilent Technologies, Santa Clara, CA, USA) and coupled to a mass spectrometer (Miyazaki et al., 2012; Müller et al., 2017). From the TMS derivatives, structures of each compound of FAs were elucidated

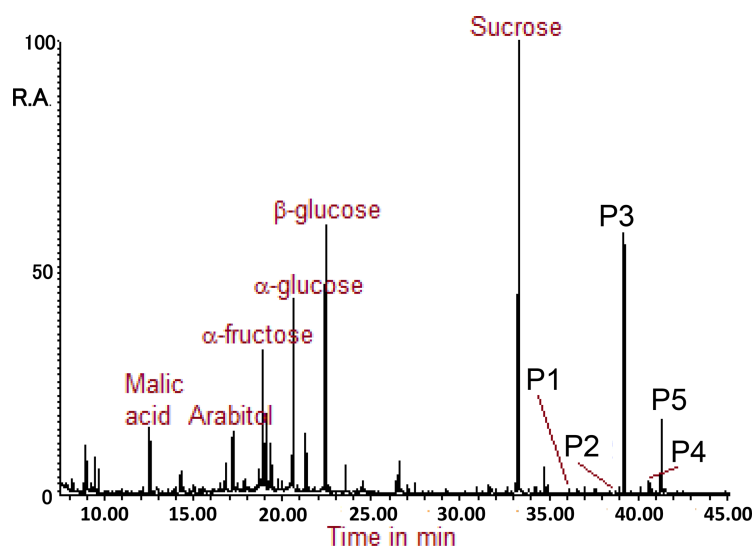

Figure 2. GC-MS total ion chromatogram obtained for the TMS derivatives. P1-P5 refer to peaks, which correspond to the secondary fatty alcohols identified in this study.

with low-resolution GC-MS (MSD5975C, Agilent), as well as with a high-resolution gas chromatograph-time-of-flight mass spectrometer (GC-TOF-MS; JMS-T100GCV, JEOL) using electron ionization (EI). Identification of each compound was made based on GC retention time, literature mass spectra, and the interpretation of mass spectrometric fragmentation patterns. In addition to FAs, sucrose and levoglucosan were also measured by the same method as described above.

\section{Identification of secondary fatty alcohols in the aerosol samples}

Figure 2 presents an example of a GC-MS total ion chromatogram (TIC) of the TMS extract of the TSP sample collected at the FHK site. In previous studies, sugar compounds have been identified with the same method of derivatization, such as arabitol, fructose, glucose, and sucrose (e.g., Miyazaki et al. 2012; Müller et al., 2017). In the present study, P1-P5 refer to peaks which were identified to be TMS derivatives of SFAs with carbon numbers of 27 and 29, the peaks of which appear in the latter part of the TIC.

Figure 3 shows an EI mass spectra of P1-P5 obtained for the TMS derivatives with their molecular structures. On the basis of the detailed interpretation of the EI mass spectral data together with their comparison to literature data (Yamamoto et al., 2008) as well as the exact mass measurements by GC-TOF-MS, the derivatives were assigned to (a) $n$-heptacosan-10-ol-TMS (P1; $\left.\mathrm{C}_{27}\right)$, (b) $n$ heptacosan-5,10-diol-diTMS (P2; $\mathrm{C}_{27}$ ), (c) $n$-nonacosan-10ol-TMS (P3; C 29 ), (d) n-nonacosan-10-13-diol-diTMS (P4; $\mathrm{C}_{29}$ ), and (e) $n$-nonacosan-5-10-diol-diTMS (P5; $\mathrm{C}_{29}$ ). The spectra of $n$-heptacosan-10-ol-TMS is characterized by the presence of ion peaks at $m / z 73,229$, and 341 (Fig. 3a). Similarly, the mass spectra of $n$-nonacosan-10-ol-TMS showed that ion peaks at $m / z 73,229$, and 369 are significant 
(a) P1: $n$-heptacosan-10-ol-TMS

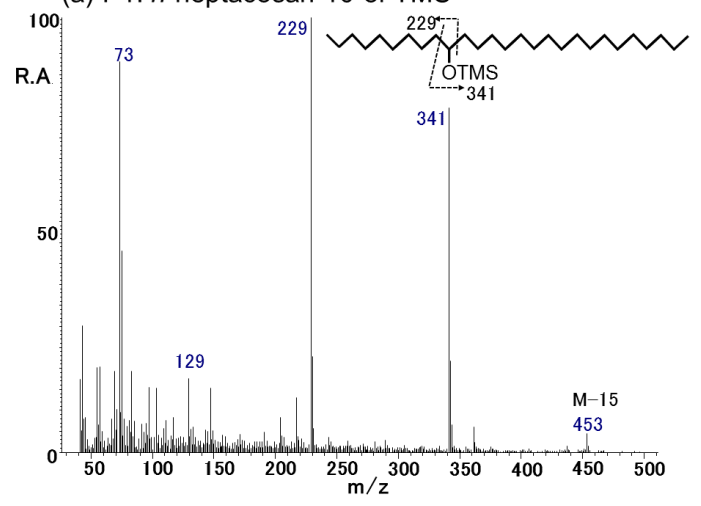

(c) P3: n-nonacosan-10-ol-TMS

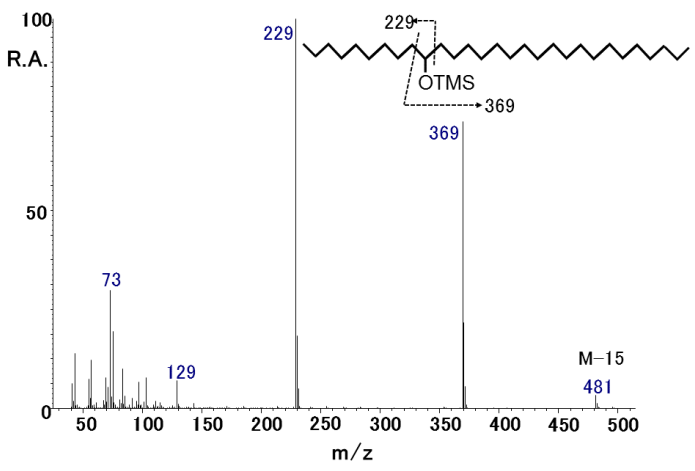

(b) P2: n-heptacosan-5,10-diol-diTMS

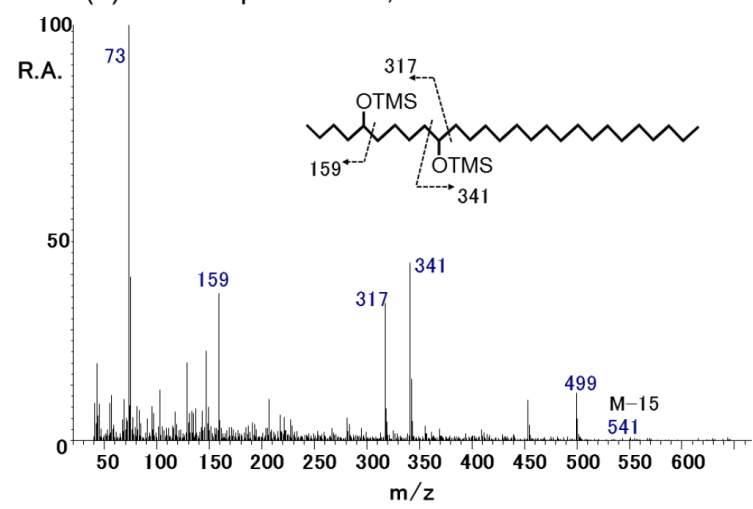

(d) P4: n-nonacosan-10,13-diol-diTMS

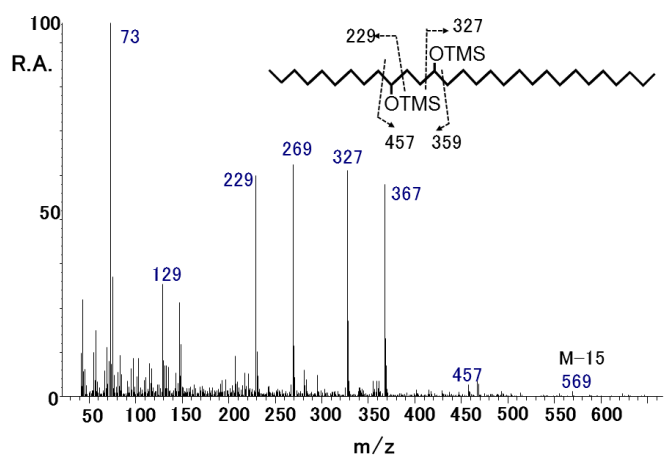

(e) P5: n-nonacosan-5-10-diol-diTMS

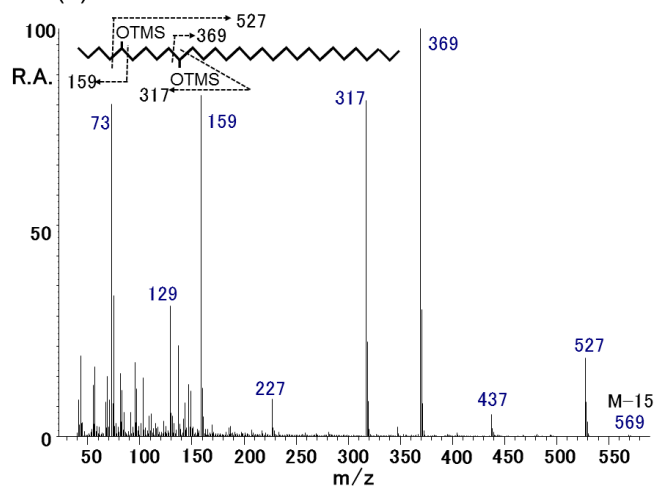

Figure 3. EI mass spectra obtained for the TMS derivatives of the identified secondary fatty alcohols. (a) P1: $n$-heptacosan-10-ol-TMS, (b) P2: n-heptacosan-5,10-diol-diTMS, (c) P3: n-nonacosan-10-ol-TMS, (d) P4: n-nonacosan-10,13-diol-diTMS, and (e) P5: n-nonacosan5-10-diol-diTMS.

(Fig. 3c). The ion at $m / z 73$, corresponding to $\left[\mathrm{Si}\left(\mathrm{CH}_{3}\right)_{3}^{+}\right]$, is characteristic for TMS derivatives containing one or more derivatized $\mathrm{OH}$ groups. Indeed, the exact mass measurements by GC-TOF-MS confirmed the estimated composition of each peak. For example, the composition of $\mathrm{P} 3$ with M15 was identified as $\mathrm{C}_{31} \mathrm{H}_{65} \mathrm{OSi}$, where its theoretical and experimental $\mathrm{m} / \mathrm{z}$ are 481.4805 and 481.4826 , respectively, with an error of $4 \mathrm{ppm}$.
The spectra of P2 (Fig. 3b), P4 (Fig. 3d), and P5 (Fig. 3e) were identified as the TMS derivatives of secondary fatty diols. The mass spectra of $n$-nonacosan-10,13-diol-diTMS (Fig. 3d) is characterized by intense signals at $m / z 73,229$, 269,327 , and 367 , whereas the spectra of $n$-nonacosan-510-diol-diTMS shows ion peaks at $m / z 159,317,369$, and 527 (Fig. 3e). Spectra with significant ion peaks at $m / z 73$, 159,317 , and 341 are produced by $n$-heptacosan-5,10-diol- 
diTMS (Fig. 3b), which was newly identified and is partly similar to the characteristics of the P1 and P5 spectra.

\section{Seasonal changes in the concentrations of the secondary fatty alcohols in the aerosols at the two forest sites}

Figure 4 displays the seasonal variations of the identified SFAs in the TSP samples at the TMK and FHK sites in 2015. Here seasonal categories of spring, summer, autumn, and winter refer to the periods March-May, JuneAugust, September-November, and December-February, respectively. The average concentrations in each seasonal category are summarized in Table 1. Among the SFAs identified, $n$-nonacosan-10-ol is the most abundant compound, followed by $n$-nonacosan-5,10-diol at both sites. The SFAs exhibited distinct seasonal changes, with the largest concentrations observed in the spring (growing season), both at the TMK $\left(101.7 \pm 100.9 \mathrm{ng} \mathrm{m}^{-3}\right)$ and the FHK $\left(211.7 \pm 231.9 \mathrm{ng} \mathrm{m}^{-3}\right)$ sites. The maximum concentrations of $n$-nonacosan-10-ol reached 268.6 and $442.1 \mathrm{ng} \mathrm{m}^{-3}$ at the TMK and FHK sites, respectively. The SFA with the second largest concentration, $n$-nonacosan-5,10-diol, showed a similar temporal variation to $n$-nonacosan-10-ol, suggesting that $n$-nonacosan-5,10-diol originated from identical or similar sources to those of $n$ nonacosan-10-ol. It is noted that the seasonal variation in concentrations of $n$-nonacosan-10-ol in 2016 was similar to that in 2015 at FHK (Fig. 4b). This similarity indicates that this seasonal trend is likely to be representative of the forest environment.

A primary plant origin of these SFAs is most likely, because the SFAs are known to be present in plant leaves; $n$ nonacosan-10-ol has been identified as a major compound in epicuticular waxes found in gymnosperm species (Tulloch, 1976; Schulten et al., 1986), such as Sequoiadendron giganteum (Yamamoto et al., 2008). Moreover, secondary fatty diols have been reported in other plant species, such as Pisum sativum (Vioque and Kolattukudy, 1997). In the atmosphere, $n$-nonacosan-10-ol was observed in smoke aerosol samples from conifers subjected to controlled burning (Oros and $\mathrm{Si}$ moneit, 2001a). Moreover, some of the common alkanols found in urban and remote island sites in spring are thought to have been emitted to the atmosphere by biomass burning (Oros and Simoneit, 2001a, b; Simoneit et al., 2004), while they also indicate an input of waxes from forests consisting of both soft and hardwoods.

In our study, a primary origin of biomass burning is unlikely because the SFAs showed no significant correlation with tracer compounds of biomass burning, such as levoglucosan with $R^{2}$ of $<0.02$ (data not shown) at both sites. Rather, the seasonal trends of the SFA concentrations are similar to that of sucrose, which is an important primary saccharide of pollen grains (Pacini, 2000) and has been used as a tracer for pollen (e.g., Miyazaki et al., 2012). Specifically,
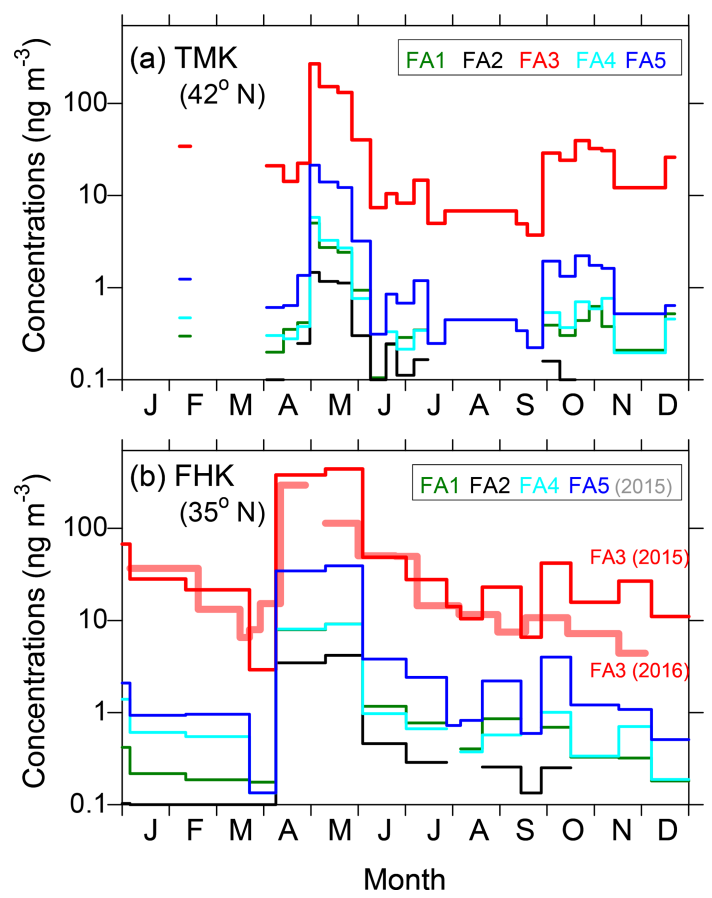

Figure 4. Temporal variations in the mass concentrations of the fatty alcohols (FAs) in the TSP samples at (a) TMK and (b) FHK sites in 2015. FA1: $n$-heptacosan-10-ol, FA2: $n$-heptacosan-5,10diol, FA3: $n$-nonacosan-10-ol, FA4: $n$-nonacosan-10,13-diol, and FA5: $n$-nonacosan-5-10-diol. The data of FA3 in 2016 are also shown for comparison.

the concentration of $n$-nonacosan-10-ol showed significant positive correlations with that of sucrose both at the TMK $\left(R^{2}=0.70\right)$ and FHK sites $\left(R^{2}=0.61\right)$. The average concentrations of $n$-nonacosan-10-ol were significantly larger than those of sucrose in the growing season at the two sites. These results suggest that the increase in the mass concentrations of $n$-nonacosan-10-ol and the other SFAs is due to large emissions of plant waxes or components thereof (i.e., fatty alcohols) from the forest leaves into the atmosphere. Our analysis also suggests that the SFAs identified here can act as tracers for primary biological aerosol particles (PBAPs) which are surface-active.

It is noted that the peak concentration of SFAs at FHK appeared in April (Fig. 4b), approximately 1 month earlier than at TMK (Fig. 4a). The difference in the appearance of the peaks is attributable to the difference in the growing season at the two sites: the growth of forest vegetation generally starts about 1 month earlier at FHK $\left(35^{\circ} \mathrm{N}\right)$ than at TMK $\left(42^{\circ} \mathrm{N}\right)$ (Nakaji et al., 2011; Takahashi et al., 2015), which is also evident from the seasonal changes in the net ecosystem production (Saigusa et al., 2008). The primary emissions of these organic compounds clearly depend on the activity of the forest vegetation and, more specifically, plant leaf phenology at these forest sites. Considering that the aerosol sampling duration of about 1-2 weeks is much longer than the timescale 
Table 1. The mass concentrations* of the secondary fatty alcohols (SFAs) identified and sucrose in TSP at TMK and FHK sites in each season in 2015 .

\begin{tabular}{|c|c|c|c|c|c|c|c|c|}
\hline & \multicolumn{4}{|c|}{ TMK 2015} & \multicolumn{4}{|c|}{ FHK 2015} \\
\hline$n$-Heptacosan-10-ol & $0.34 \pm 0.16$ & $1.85 \pm 1.90$ & $0.27 \pm 0.32$ & $0.31 \pm 0.23$ & $0.54 \pm 0.40$ & $4.37 \pm 4.86$ & $0.78 \pm 0.38$ & $0.34 \pm 0.28$ \\
\hline$n$-Nonacosan-10-ol & $24.1 \pm 11.1$ & $102 \pm 101$ & $13.3 \pm 12.3$ & $23.5 \pm 13.9$ & $68.5 \pm 40.8$ & $212 \pm 232$ & $28.9 \pm 19.1$ & $22.8 \pm 15.2$ \\
\hline$n$-Nonacosan-10,13-diol & $0.37 \pm 0.16$ & $2.12 \pm 2.23$ & $0.24 \pm 0.28$ & $0.42 \pm 0.32$ & $1.40 \pm 0.79$ & $4.47 \pm 4.79$ & $0.67 \pm 0.30$ & $0.51 \pm 0.44$ \\
\hline$n$-Nonacosan-5,10-diol & $0.80 \pm 0.38$ & $8.36 \pm 8.76$ & $0.99 \pm 1.03$ & $1.34 \pm 0.78$ & $2.59 \pm 1.96$ & $18.7 \pm 21.1$ & $2.35 \pm 1.50$ & $1.72 \pm 1.54$ \\
\hline
\end{tabular}

* Values are averages $\left(\mathrm{ng} \mathrm{m}^{-3}\right)$ with \pm 1 standard deviation. LOD is the limit of detection.

Table 2. The average concentrations of $n$-nonacosan-10-ol, $n$-nonacosan-5,10-diol, and sucrose in the submicrometer particles and the fractions of their mass to the TSP mass at the TMK site in 2015.

\begin{tabular}{|c|c|c|c|c|c|c|}
\hline & $n$-Nonacosan-10-ol ${ }^{\mathrm{a}}$ & $\begin{array}{l}\text { Sub- } \mu \mathrm{m} / \text { TSP ratio of } \\
n \text {-nonacosan-10-ol }\end{array}$ & $n$-Nonacosan-5,10-diol ${ }^{\mathrm{a}}$ & $\begin{array}{l}\text { Sub- } \mu \mathrm{m} / \mathrm{TSP} \text { ratio of } \\
n \text {-nonacosan-5,10-diol }\end{array}$ & Sucrose ${ }^{\mathrm{a}}$ & $\begin{array}{r}\text { Sub- } \mu \mathrm{m} / \text { TSP ratio } \\
\text { of sucrose }\end{array}$ \\
\hline Spring & $69.6 \pm 125$ & $0.68 \pm 1.98$ & $5.24 \pm 11.7$ & $0.65 \pm 2.39$ & $6.28 \pm 6.27$ & $0.29 \pm 0.12$ \\
\hline Autumn & $6.66 \pm 6.80$ & $0.28 \pm 0.11$ & $0.20 \pm 0.39$ & $0.15 \pm 0.09$ & $0.25 \pm 0.18$ & $0.36 \pm 0.19$ \\
\hline
\end{tabular}

a Values are average concentrations $\left(\mathrm{ng} \mathrm{m}^{-3}\right)$ with \pm 1 standard deviation. ${ }^{\mathrm{b}}$ Values are average ratios (ng ng $\left.{ }^{-1}\right)$ with \pm 1 standard deviation.

of transport of particles in the forest regions, the aerosol particles collected in this study were likely influenced by biogenic emissions from the whole area of each forest region. In contrast to the growing season, seasons in which the lowest concentrations were observed are not clear from Fig. 4. Large standard deviations of the average values in winter, summer, and autumn at the two sites (Table 1) mean that the difference in the average concentrations is mostly insignificant for these seasons. This is attributable to various factors (e.g., the difference in the emission strength and photochemical activity in the atmosphere) which need to be further investigated in a future study.

Figure 5 presents seasonal averages of the mass concentrations and particle size fractions of $n$-nonacosan-10-ol observed at the TMK site. The average values and the fractions of their mass to the TSP mass at the TMK site in 2015 are also summarized in Table 2. In spring, the mass of $n$-nonacosan-10-ol in the submicrometer size ranges accounts for $\sim 68 \%$ of the TSP mass, the fraction of which is much larger than that in summer $(\sim 10 \%)$ and autumn $(\sim 28 \%)$. Similarly, the average mass fraction of submicrometer $n$-nonacosan-5,10-diol in TSP is $65 \%$ in spring, whereas the mass fraction is $1 \%$ and $15 \%$ in summer and autumn, respectively. Our result is similar to that of Kavouras and Stephanou (2002), who also measured particle size distributions of $n$-alkanols $\left(<\mathrm{C}_{26}\right)$ at Eucalyptus and conifer forests in summer to show clear bimodal size distributions with $\sim 40 \%$ of the mass residing in particles with diameters smaller than $0.96 \mu \mathrm{m}$. In general, the majority of the mass of PBAPs resides in supermicrometer particles. Indeed, the

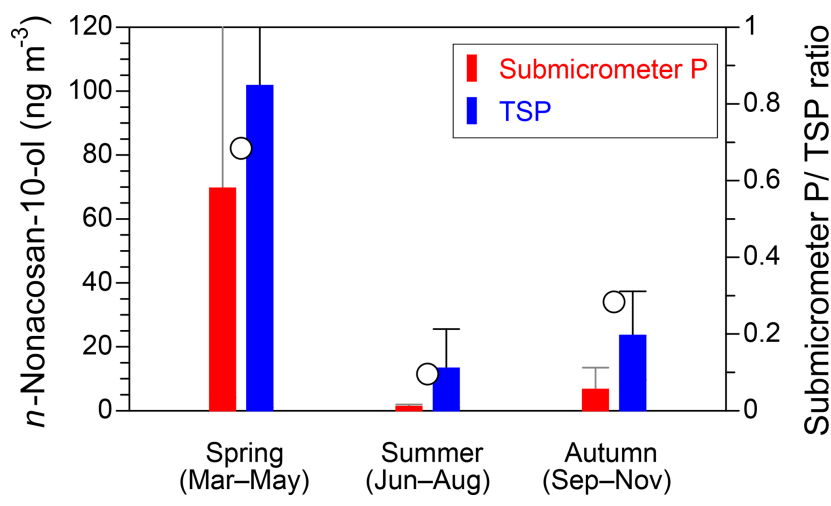

Figure 5. Seasonal averages of the mass concentrations of $n$ nonacosan-10-ol in the submicrometer particles (P) (red) and TSP (blue) samples obtained at the TMK site. The error bars show the standard deviations, and open circles indicate the mass ratios of the submicrometer $\mathrm{P} / \mathrm{TSP}$.

mass fractions of sucrose in the submicrometer size range were $29 \%$ in spring, showing that the majority $(\sim 70 \%)$ of the mass resides in the supermicrometer size range in the growing season (Table 2). In contrast to the typical PBAPs tracers, our result suggests that a significant fraction of the SFAs can be attributed to the submicrometer particles in the growing season. 


\section{Conclusions}

Secondary fatty alcohols with carbon numbers of 27 and 29 were identified in atmospheric aerosol samples collected throughout the year at two different deciduous forest sites. As far as we know, this study is the first to identify fatty diols, such as $n$-heptacosan-5,10-diol, in atmospheric aerosol samples and to show the seasonal variations in their concentrations in the forest atmosphere.

Among the identified SFAs, $n$-nonacosan-10-ol was the most abundant molecular compound, followed by $n$ nonacosan-5,10-diol. The SFAs showed pronounced peaks in the growing season at both forest sites. In spring, the concentrations of $n$-nonacosan-5,10-diol were much larger than those of sucrose. Moreover, the concentrations of the identified SFAs showed significant positive correlations with those of sucrose at the two sites. These results indicate that the SFAs originated mostly from plant wax. The difference in the peak appearance of the SFA concentrations at the two sites indicates that the primary emissions of these organic compounds clearly reflect the activity of the forest vegetation such as plant leaf phenology at the forest sites.

In the growing season, the fraction of $n$-nonacosan-10-ol in the submicrometer size range accounted for $\sim 70 \%$ of the TSP mass. Similarly, the average mass of submicrometer $n$ nonacosan-5,10-diol in TSP accounted for $65 \%$ of the mass of TSP in spring. These fractions were much larger than those in the other seasons, suggesting that a significant fraction of the SFAs was attributed to the submicrometer particles in the growing season. This study demonstrates that the SFAs identified, particularly $n$-nonacosan- 10 -ol and $n$-nonacosan5,10-diol, can be used as effective tracers for PBAPs with surface-active organic matter.

Data availability. Data from measurements are available upon request from the corresponding author.

Author contributions. YM designed the research, led the overall study, and wrote the manuscript. DG performed the experiments with the GC-MS. TH and YT coordinated the aerosol samplings at the research sites. YT and YM made aerosol samplings. DG, YM, and ET analyzed the data.

Competing interests. The authors declare that they have no conflict of interest.

Acknowledgements. We thank the staff of the Instrumental Analysis Division in the Global Facility Center of the Creative Research Institution at Hokkaido University for their help with the GC-TOFMS measurements of the samples.
Financial support. This research has been supported by JSPS KAKENHI (grant no. JP16H02931).

Review statement. This paper was edited by Sebastiaan Luyssaert and reviewed by Magda Claeys and one anonymous referee.

\section{References}

Cantrell, W. and Robinson, C.: Heterogeneous freezing of ammonium sulfate and sodium chloride solutions by long chain alcohols, Geophys. Res. Lett., 33, L07802, https://doi.org/10.1029/2005GL024945, 2006.

Carslaw, K. S., Boucher, O., Spracklen, D. V., Mann, G. W., Rae, J. G. L., Woodward, S., and Kulmala, M.: A review of natural aerosol interactions and feedbacks within the Earth system, Atmos. Chem. Phys., 10, 1701-1737, https://doi.org/10.5194/acp10-1701-2010, 2010.

Dahl, K. A., Oppo, D. W., Eglinton, T. I., Hughen, K. A., Curry, W. B., and Sirocko, F.: Terrigenous plant wax inputs to the Arabian Sea: Implications for the reconstruction of winds associated with the Indian Monsoon, Geochim. Cosmochim. Ac., 69, 25472558, 2005.

Gagosian R. B., Peltzer, E. T., and Zafiriou, O. C.: Atmospheric transport of continentally derived lipids to the tropical North $\mathrm{Pa}$ cific, Nature, 291, 312-314, 1981.

Gill, P. S., Graedel, T. E., and Weschler, C. J.: Organic films on atmospheric aerosol particles, fog droplets, cloud droplets, raindrops, and snowflakes, Rev. Geophys. Space Ge., 21, 903-920, 1983.

Hiura, T.: Stochasticity of species assemblage of canopy trees and understory plants in a temperate secondary forest created by major disturbances, Ecol. Res., 16, 887-893, 2001.

Hiura, T.: Estimation of aboveground biomass and net biomass increment in a cool temperate forest on a landscape scale, Ecol. Res., 20, 271-277, 2005.

Kavouras, I. G. and Stephanou, E. G.: Particle size distribution of organic primary and secondary aerosol in urban, background marine, and forest atmosphere, J. Geophys. Res., 107, 4069, https://doi.org/10.1029/2000JD000278, 2002.

Knopf, D. A., Alpert, P. A., and Wang, B.: The role of organic aerosol in atmospheric ice nucleation: A review, ACS Earth Space Chem., 2, 168-202, https://doi.org/10.1021/acsearthspacechem.7b00120, 2018.

Miyazaki, Y., Fu, P. Q., Kawamura, K., Mizoguchi, Y., and Yamanoi, K.: Seasonal variations of stable carbon isotopic composition and biogenic tracer compounds of water-soluble organic aerosols in a deciduous forest, Atmos. Chem. Phys., 12, 13671376, https://doi.org/10.5194/acp-12-1367-2012, 2012.

Mochizuki, T., Miyazaki, Y., Ono, K., Wada, R., Takahashi, Y., Saigusa, N., Kawamura, K., and Tani, A.: Emissions of biogenic volatile organic compounds and subsequent formation of secondary organic aerosols in a Larix kaempferi forest, Atmos. Chem. Phys., 15, 12029-12041, https://doi.org/10.5194/acp-1512029-2015, 2015.

Mudge, S. M.: Fatty alcohols - a review of their natural synthesis and environmental distribution, Exec. Summ. Soap Deterg. Assoc., 132, 1-141, 2015. 
Müller, A., Miyazaki, Y., Tachibana, E., Kawamura, K., and Hiura, T.: Evidence of a reduction in cloud condensation nuclei activity of water-soluble aerosols caused by biogenic emissions in a cool-temperate forest, Sci. Rep.-UK, 7, 8452, https://doi.org/10.1038/s41598-017-08112-9, 2017.

Nakaji, T., Oguma, H., and Hiura, T.: Ground-based monitoring of the leaf phenology of deciduous broad-leaved trees using high resolution NDVI camera images, J. Agric. Meteorol., 67, 65-74, 2011.

Oros, D. R. and Simoneit, B. R. T.: Identification and emission factors of molecular tracers in organic aerosols from biomass burning Part 1. Temperate climate conifers, Appl. Geochem., 16, 1513-1544, 2001a.

Oros, D. R. and Simoneit, B. R. T.: Identification and emission factors of molecular tracers in organic aerosols from biomass burning Part 2. Deciduous trees, Appl. Geochem., 16, 1545-1565, 2001b.

Pacini, E.: From anther and pollen ripening to pollen presentation, Plant Syst. Evol., 222, 19-43, 2000.

Popovitz-Biro, R., Wang, J. L., Majewski, J., Shavit, E., Leiserowitz, L., and Lahav, M.: Induced freezing of supercooled water into ice by self-assembled crystalline monolayers of amphiphilic alcohols at the air-water interface, J. Am. Chem. Soc., 116, 1179-1191, 1994.

Pummer, B. G., Budke, C., Augustin-Bauditz, S., Niedermeier, D., Felgitsch, L., Kampf, C. J., Huber, R. G., Liedl, K. R., Loerting, T., Moschen, T., Schauperl, M., Tollinger, M., Morris, C. E., Wex, H., Grothe, H., Pöschl, U., Koop, T., and Fröhlich-Nowoisky, J.: Ice nucleation by watersoluble macromolecules, Atmos. Chem. Phys., 15, 4077-4091, https://doi.org/10.5194/acp-15-4077-2015, 2015.

Saigusa N., Yamamoto S., Hirata R., Ohtani Y., Ide R., Asanuma J., Gamo M., Hirano T., Kondo H., Kosugi Y.: Temporal and spatial variations in the seasonal patterns of $\mathrm{CO}_{2}$ flux in boreal, temperate, and tropical forests in East Asia, Agr. Forest Meteorol., 148, 700-713, 2008.
Schulten, H.-R., Simmleit, N., and Rump, H. H.: Soft ionization mass spectrometry of epicuticular waxes isolated from coniferous needles, Chem. Phys. Lipids, 41, 209-224, 1986.

Simoneit, B. R. T., Kobayashi, M., Mochida, M., Kawamura, K., Lee, M., Lim, H.-J., Turpin, B. J., and Komazaki, Y.: Composition and major sources of organic compounds of aerosol particulate matter sampled during the ACE-Asia campaign, J. Geophys. Res., 109, D19S10, https://doi.org/10.1029/2004JD004598, 2004.

Takahashi Y., Saigusa N., Hirata R., Ide R., Fujinuma Y., Okano T., and Arase T.: Characteristics of temporal variations in ecosystem $\mathrm{CO}_{2}$ exchange in a temperate deciduous needle-leaf forest in the foothills of a high mountain, J. Agric. Meteorol., 71, 302-317, 2015.

Tulloch, A. P.: Chemistry of waxes of higher plants, chemistry and biochemistry of natural waxes, edited by: Kolattukudy, P. E., Amsterdam, Elsevier, 235-287, 1976.

Urakawa, R., Ohte, N., Shibata, H., Tateno, R., Hishi, T., Fukushima, K., Inagaki, Y., Hirai, K., Oda, T., Oyanagi, N., Nakata, M., Toda, H., Tanaka, K., Fukuzawa, K., Watanabe, T., Tokuchi, N., Nakaji, T., Saigusa, N., Yamao, Y., Nakanishi, A., Enoki, T., Ugawa, S., Hayakawa, A., Kotani, A., Kuroiwa, M., and Isobe, K.: Biogeochemical nitrogen properties of forest soils in the Japanese archipelago, Ecol. Res., 30, 1-2, https://doi.org/10.1007/s11284-014-1212-8, 2015.

Vioque, J. and Kolattukudy, P. E.: Resolution and purification of an aldehydegenerating and an alcohol-generating fatty acyl-CoA reductase from pea leaves (Pisum sativum L), Arch. Biochem. Biophys., 340, 64-72, 1997.

Yamamoto, S., Otto, A., and Simoneit, B. R. T.: GC-MS analysis of wax in leaf of Sequoiadendron giganteum, Sequoioideae, Cuprressaceae, Res. Org. Geochem., 23/24, 159-171, 2008 (in Japanese). 